\title{
Impacts of Limestone Particle Size on the Performance of Flexible Wood Fiber Composite Floor
}

\author{
Hongcheng He, ${ }^{1}$ Jinling Nie, ${ }^{1}$ and Jing Wang ${ }^{2}$ \\ ${ }^{1}$ Hunan Academy of Forestry, Shaoshan South Road, Changsha, Hunan 410004, China \\ ${ }^{2}$ Centre of Excellence in Engineered Composite, University of Southern Queensland, Toowoomba, QLD 4350, Australia \\ Correspondence should be addressed to Hongcheng He; xbd9818@163.com and Jing Wang; jing.wang@usq.edu.au
}

Received 25 June 2014; Revised 20 August 2014; Accepted 24 August 2014

Academic Editor: Jin Zhu

Copyright (c) 2015 Hongcheng He et al. This is an open access article distributed under the Creative Commons Attribution License, which permits unrestricted use, distribution, and reproduction in any medium, provided the original work is properly cited.

\begin{abstract}
Sustainable wood floor (WFF), produced from natural plants, is a sort of novel green and ecofriendly composite floor, which has been attracting more and more attention in the world. WFF also gives a solution of utilizations of agricultural wastes, such as bamboo mats and hemp hurd. The additive limestone powder plays key role in the performance of flexible bamboo composite floor, so, in this paper, the effects of limestone size and size distributions were investigated. The best particle size distributions of limestone are $25 \mathrm{wt} \%$ of $48 \mu \mathrm{m}, 25 \mathrm{wt} \%$ of $106 \mu \mathrm{m}$, and $50 \mathrm{wt} \%$ of $160 \mu \mathrm{m}$. The as-obtained WFF has good elasticity, good affinity, and strong comfortableness as well as free formaldehyde release.
\end{abstract}

\section{Introduction}

With globally rapid development of industrialization and urbanization, energy saving and greenhouse gas (GHG) mitigation have become ones of the most extensive issues [1-5]. Flexible wood fiber floor, prepared by special processing technology using nature fibers (such as bamboo, hemp, cotton, and other woods), PVC, limestone powders, flexible agent, and raw materials, is one kind of new green and environmental protection composite floors [6]. Natural fibres can also be widely applied furniture veneer, integral cupboard, and decorative materials $[7,8]$.

The natural fibre reinforced composites have competitive advantages, such as (i) being green and ecofriendly: the products do not contain urea formaldehyde, phenolic aldehyde, or aldehydes resin and are free of formaldehyde [9] and it is also free of wastewater and exhaust gas release during the manufacturing process; (ii) having excellent abrasive resistance [10]: the wear-resisting revolution is as high as 300,000 , compared with traditional floor materials 13,000 and the high-performance aggrandizement wood floor 20,000; (iii) having higher quality and better elasticity [11]: this product could become thinner, lighter, and stronger than conventional materials, so that it enables the modern high buildings weight-bearing and space saving [8] and due to the good elastic recovery under heavy shock load, the workrelated injury can be dramatically reduced and, at the same time, the elastic recovery may reduce the damage to the floor; (iv) being waterproof, antiskid, antibacterial and [1214]: the natural fibres are easily modified and treated to change their surface physical and chemical structure, so this composite floor has excellent waterproof and antibacterial properties and the flame retardant can reach the B1 level of GB8624-1997 [15]; (v) being antistatic: due to the natural characteristic of natural fibers and limestone, the floor can be permanently antistatic [16]; (vi) being mute and noise reducing [17]: WFF contains abundant wood fibers which have good sound absorbability, so this composite could be utilized to produce sound absorbing decorative board [18].

During the development of wood fibre floor, the addition of limestone is a must to enhance the mechanical properties and improve other functional features. However, the impacts of limestone particle size and the size distribution on the performance of composite floor are still not clear. This paper is the first to systematically investigate those impact factors. 
TABLE 1: The dimension of bamboo fibre.

\begin{tabular}{lcccc}
\hline & Length, $\mu \mathrm{m}$ & Width, $\mu \mathrm{m}$ & Inner diameter, $\mu \mathrm{m}$ & Length-width ratio \\
\hline Average & 89.84 & 36.60 & 29.42 & 2.45 \\
Coefficient of variation & $24 \%$ & $13 \%$ & $14 \%$ & $27 \%$ \\
\hline
\end{tabular}

TABLE 2: Effects of limestone particle size and size distribution on the performance of wood composite floor.

\begin{tabular}{|c|c|c|c|c|c|c|c|c|}
\hline Number & Size/mesh (portion) & $\mathrm{MOR} / \mathrm{MPa}$ & $\mathrm{MOE} / \mathrm{MPa}$ & Shock strength/MPa & $\mathrm{IB} / \mathrm{MPa}$ & Density/g/ $\mathrm{cm}^{3}$ & $\mathrm{TS} / \%$ & Thermal expansion ratio/\% \\
\hline 1 & No limestone added & 16.6 & 1396 & 10.9 & 2.98 & 1.18 & 1.55 & 1.83 \\
\hline 2 & $48(100)$ & 18.7 & 1436 & 11.9 & 2.35 & 1.13 & 0.56 & 1.33 \\
\hline 3 & $106(100)$ & 20.6 & 1723 & 13.6 & 1.98 & 0.98 & 0.78 & 1.16 \\
\hline 4 & $160(100)$ & 28.3 & 1950 & 19.9 & 1.26 & 0.75 & 1.69 & 0.92 \\
\hline 5 & $\begin{array}{c}48(25) \\
106(25) \\
160(50)\end{array}$ & 27.2 & 1679 & 13.6 & 1.68 & 0.72 & 1.56 & 0.98 \\
\hline 6 & $\begin{array}{c}48(30) \\
106(25) \\
160(45)\end{array}$ & 23.5 & 1586 & 13.1 & 1.76 & 0.65 & 1.38 & 1.13 \\
\hline 7 & $\begin{array}{c}48(35) \\
106(25) \\
160(40) \\
\end{array}$ & 21.6 & 1532 & 12.5 & 1.81 & 0.61 & 1.33 & 1.21 \\
\hline
\end{tabular}

\section{Materials and Methods}

2.1. Materials. Bamboo fiber (moisture $8 \%$, ash less than $3 \%$ ) was obtained from Shandong Xincheng Wood Fiber Powder Corporation (China). PVC was received from Qilu Petrochemical Company (China). Limestone powder (particle size $48 \mu \mathrm{m}, 106 \mu \mathrm{m}$, and $160 \mu \mathrm{m}$ ) was supplied by Hebei Lingshou Tianhao Minerals Processing Factory. Vinyl chloridevinyl acetate copolymer (EVA-1) was purchased from Beijing Hua'er Corporation. The polar fibre dimension is shown in Table 1 and the fibre was used as received.

2.2. Equipment and Instruments. WFF was carried out by using independent flexible bamboo fiber floor production line; the mechanic properties were tested by WDT- 5 tension and compression spring tester; DMA242 was applied to characterize the mechanical properties of materials as a function of time and temperature.

2.3. Test Methodologies of Mechanical Properties. To test modulus of rupture (MOR) and modulus of elasticity (MOE), samples were prepared according to the standard of GB/T9341-2000. Standard of ASTM D 256-06 was applied to measure shock strength. Other properties such as the internal bond (IB) strength, sample density, the thickness swelling (TS) rate of water absorption, and the hold screw force were carried out referring to the standard of GB-T 1177182009, GB/T1033.1-2008 GB/T1034-1998, and GB 11718.9-1989, respectively. The thickness swelling ratio was tested at $20^{\circ} \mathrm{C}$ for 24 hours.

\subsection{Preparation of Wood Floor}

2.4.1. Technological Process. See Figure 1.

2.4.2. Main Process Parameters and Facilities. Figure 2 shows the main preparing process of wood floor and wooden homogeneity hollow coiling molding. The main facilities required in those process are listed as powder microwave dryer, mixing agitator, kneading extruder, high sheeting open miller, high calendaring and coating machine, oil pressure cooling and shaping machine, traction and cutting machine, mould press machine, edge cutter, and coater.

To prepare wood floor, wood powder was milled to 80120 mesh in size and dried at $100^{\circ} \mathrm{C}$ for 1 hour, with the moisture being less than $8 \%$. The dried powder then was mixed with EVA-1, PVC, and limestone for $30 \mathrm{~min}$ and cured at $100-180^{\circ} \mathrm{C}$ for $15-20 \mathrm{~min}, 80-120^{\circ} \mathrm{C}$ for $5-10 \mathrm{~min}, 60-100^{\circ} \mathrm{C}$ for $3-5 \mathrm{~min}$, and $30-50^{\circ} \mathrm{C}$ for $3-5 \mathrm{~min}$, respectively, followed by edge cutting and polishing. In all samples preparation, the ratio of bamboo fiber powder, limestone, PVC resin, and accessories is $30: 40: 25: 5$.

\section{Results and Discussion}

The impacts of limestone particle size and size distribution on the performance of wood fibre reinforced composite floor are shown in Table 2 and Figure 3. All results are average values tested three times. Table 2 shows that all features improved after limestone particle was added to the composites. During the manufacturing of flexible bamboo fiber composite floor, 


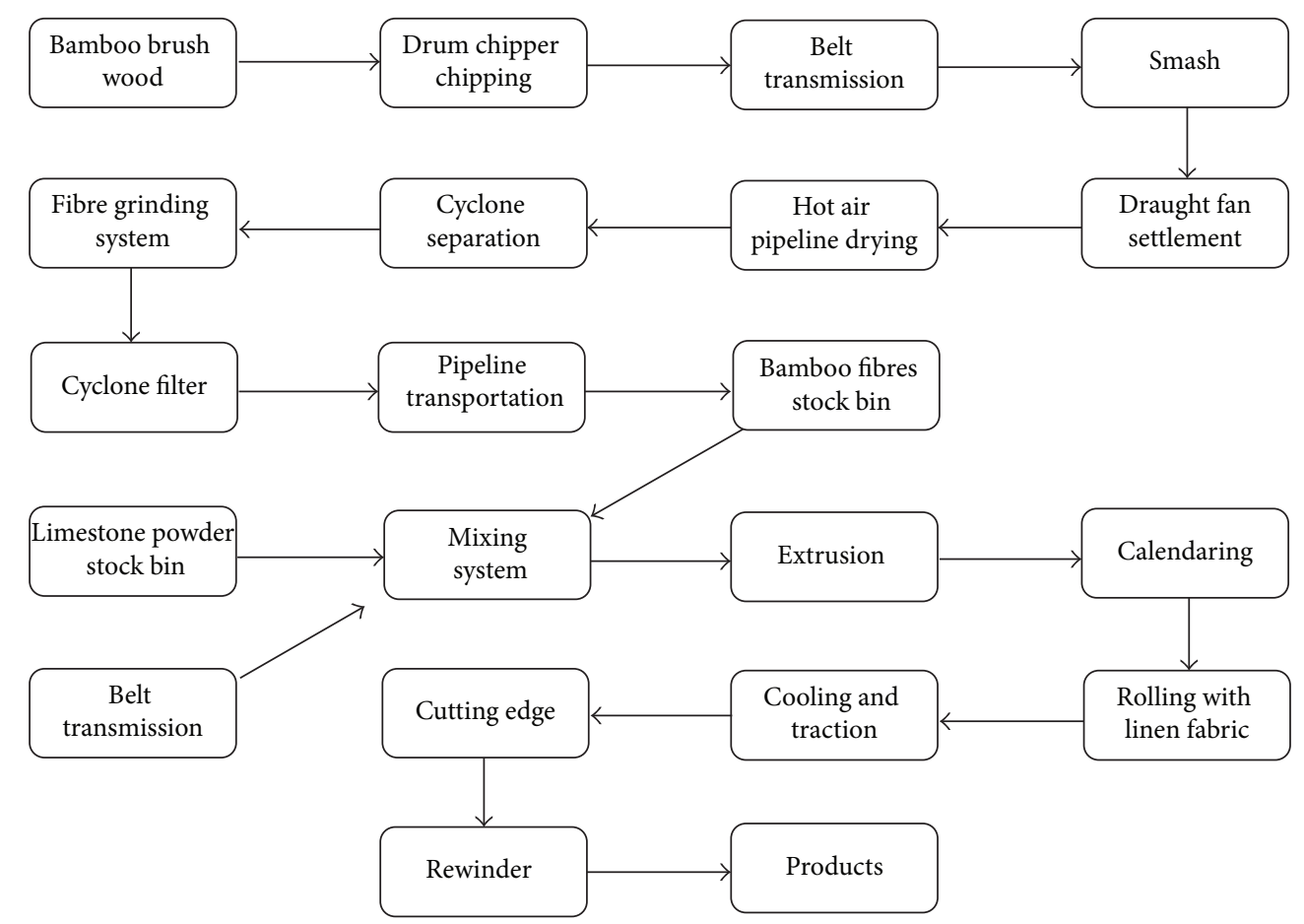

FIGURE 1: The strategy of wood composite panel preparation.

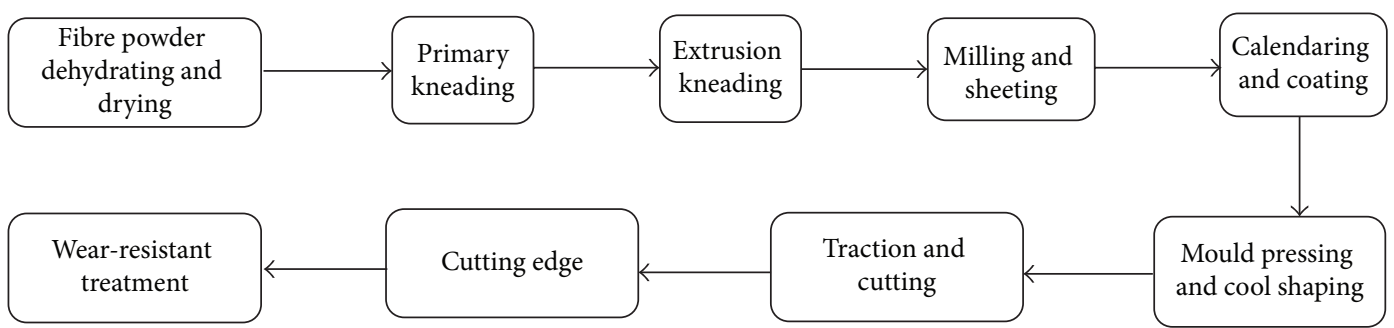

FIGURE 2: Wood floor and wooden fiber homogeneity hollow coiling molding process.

the size of limestone and the size distribution play key role on the mechanical properties of obtained composites. It is clear from Figures 3(a), 3(b), and 3(c) that composites reinforced with smaller sized limestone have lower modulus of rupture (MOR) and modulus of elasticity (MOE), meanwhile, the internal bonding (IB) strength shows decreasing trend with the increase of limestone size. Because the smaller sized powders have larger specific surface area (porosity), the smaller sized limestone has better adhesion strength with resin. As a result, its physical property is closer to plastic with better flexibility. The larger sized limestone contributes higher MOR and MOE to the composite.

To carry out better composite floor, different sized limestone powder was mixed to reinforce composite mats. When the ratio of different sized limestone powder $48 \mu \mathrm{m} / 106 \mu \mathrm{m} / 160 \mu \mathrm{m}$ is $25 / 25 / 50$, the obtained composite mats have not only optimum MOR, MOE, and internal bonding strength, but also better flexibility and enough strength, which makes it a great potential in the application as composite floor.

Figure 3(d) shows that the shock strength of WFF increases with the increase of particle size. The shock strength reaches the largest value when the limestone particle size is $160 \mu \mathrm{m}$. However, for the mixture limestone powder, the content increase of large sized particle results in the decrease of shock strength. Meanwhile, the high ratio of big sized limestone powder leads to the density declining (Figure 3(e)). This is because that with the increase of large sized powder content/distribution, the number of pores and fibres in the composite will increase so that the interface bonding strength will decrease.

Figures 3(f) and 3(g) reveal the effects of limestone size and size distribution on the TS and thermo expansion ratio. They state that the increase of small sized powder ratio leads to the increase of TS and thermal expansion rate of obtained composites. The reason is that the smaller sized particle has 


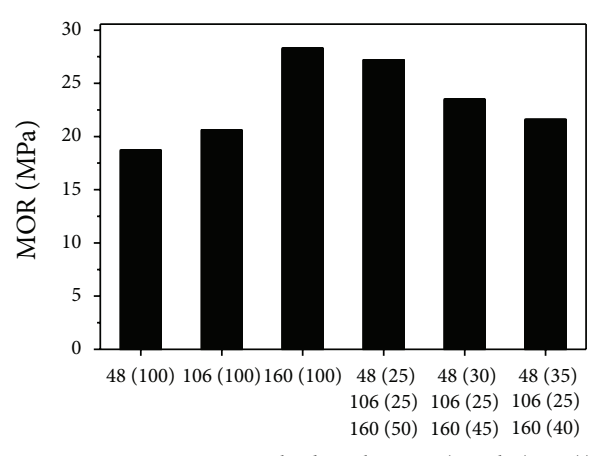

Limestone particle distribution (mesh (wt\%))

(a)

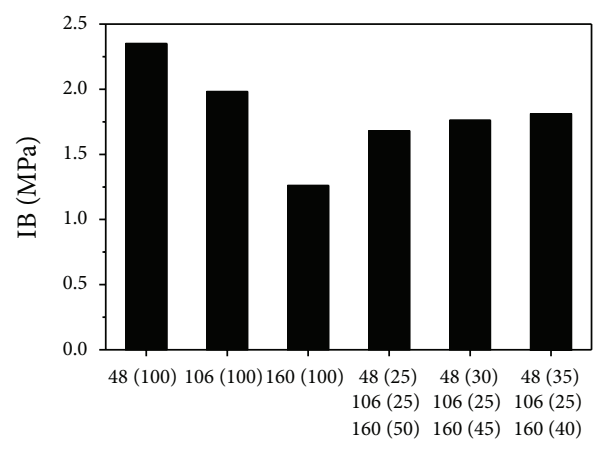

Limestone particle distribution (mesh (wt\%))

(c)

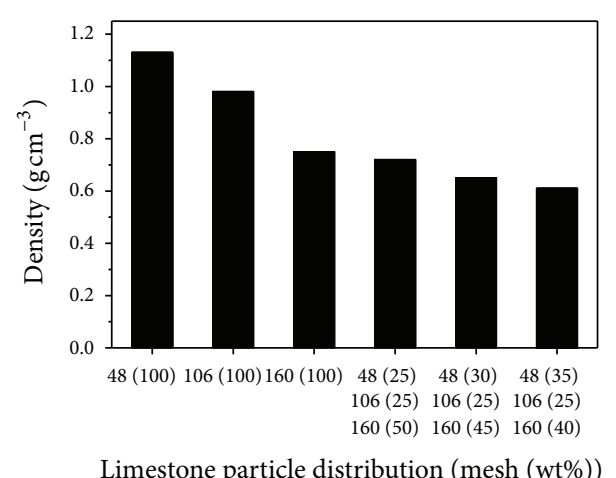

(e)

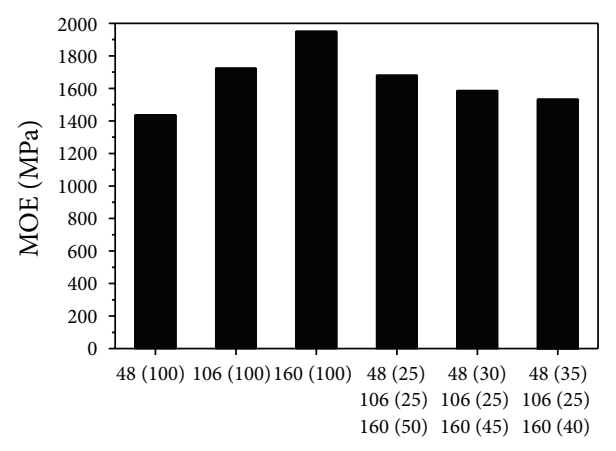

Limestone particle distribution (mesh (wt\%))

(b)

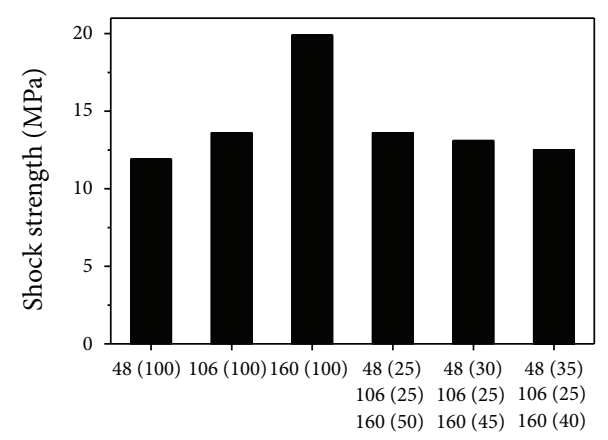

Limestone particle distribution (mesh (wt\%))

(d)

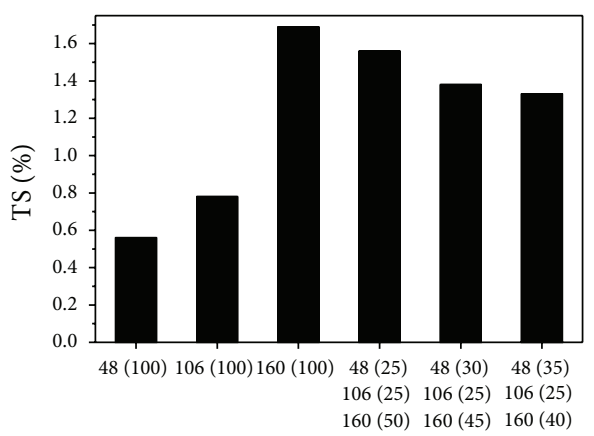

Limestone particle distribution (mesh (wt\%))

(f)

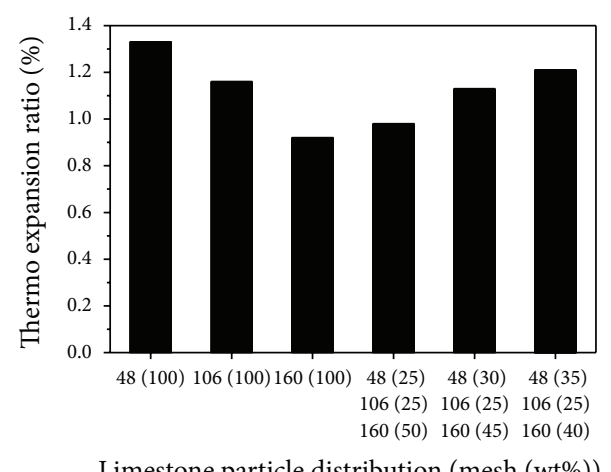

(g)

FIGURE 3: Effects of limestone particle size and size distribution on (a) MOR; (b) MOE; (c) IB; (d) shock strength; (e) density; (f) TS; and (g) thermo expansion rate. 
better combination dens which will decrease the swelling ratio of water absorption. On the other hand, with the increase of particle size (or large sized particle distribution), the lattice distortion at the interfacial zone will become harder because large limestone requires higher thermally deforming; as a result, the thermal expansion becomes lower [19].

\section{Conclusions}

The optimum features of flexible bamboo fiber composite floor prepared in this paper were tested as follows: bending strength $28.3 \mathrm{MPa}, \mathrm{MOE} 1950 \mathrm{MPa}$, shock strength $19.9 \mathrm{KJ} / \mathrm{m}^{2}$, internal bonding strength $2.35 \mathrm{MPa}$, TS $0.56 \%$, thermal expansion rate 0.92 , and density $0.61 \mathrm{~g} / \mathrm{cm}^{3}$.

The performance of wood composite floor was affected by the limestone size and size distribution. Considering and comparing all impact factors, the optimum limestone powder size ratio is concluded as $48 \mu \mathrm{m}$ ( 25 portion), $106 \mu \mathrm{m}$ (25 portion), and $160 \mu \mathrm{m}$ (50 portion).

The as-prepared wood composite floor material has good elasticity, affinity, and strong comfortableness. This composite was tested to match the China national standards requirement for man-made floor materials and has potential commercialization.

\section{Conflict of Interests}

The authors declare that there is no conflict of interests regarding the publication of this paper.

\section{Acknowledgment}

The project was financially supported by Chinese State Forestry Administration 948 Project, Natural Wood Reinforced Composite Key Technology Introduction (2011-4-11).

\section{References}

[1] B. Jiang, Z. Sun, and M. Liu, "China's energy development strategy under the low-carbon economy," Energy, vol. 35, no. 11, pp. 4257-4264, 2010.

[2] S. Luo and A. N. Netravali, "Interfacial and mechanical properties of environment-friendly "green" composites made from pineapple fibers and poly(hydroxybutyrate-co-valerate) resin," Journal of Materials Science, vol. 34, no. 15, pp. 3709-3719, 1999.

[3] S. Luo and A. N. Netravali, "Mechanical and thermal properties of environment-friendly "green" composites made from pineapple leaf fibers and poly(hydroxybutyrate-co-valerate) resin," Polymer Composites, vol. 20, no. 3, pp. 367-378, 1999.

[4] S. Nam and A. N. Netravali, "Green composites. I. Physical properties of ramie fibers for environment-friendly green composites," Fibers and Polymers, vol. 7, no. 4, pp. 372-379, 2006.

[5] Y. Wang, W. Ji, X. Yu et al., "The impact of urbanization on the annual average temperature of the past 60 years in Beijing," Advances in Meteorology, vol. 2014, Article ID 374987, 9 pages, 2014.
[6] J. Holbery and D. Houston, "Natural-fiber-reinforced polymer composites in automotive applications," JOM, vol. 58, no. 11, pp. 80-86, 2006.

[7] U. L. Ahlstedt, E. Lussi, and S. A. Ryden, "Method of making decorative laminated products such as tiles, panels or webs from cellulosic materials," US Patent 4,420,351, 1983.

[8] R. K. Cullen, M. M. Singh, and J. Summerscales, "Characterisation of natural fibre reinforcements and composites," Journal of Composites, vol. 2013, Article ID 416501, 4 pages, 2013.

[9] H. Kalaycioglu and G. Nemli, "Producing composite particleboard from kenaf (Hibiscus cannabinus L.) stalks," Industrial Crops and Products, vol. 24, no. 2, pp. 177-180, 2006.

[10] M. Saxena, R. K. Morchhale, P. Asokan, and B. K. Prasad, "Plant fiber industrial waste reinforced polymer composites as a potential wood substitute material," Journal of Composite Materials, vol. 42, no. 4, pp. 367-384, 2008.

[11] I. S. Aji, S. M. Sapuan, E. S. Zainudin, and K. Abdan, "Kenaf fibres as reinforcement for polymeric composites: a review," International Journal of Mechanical and Materials Engineering, vol. 4, no. 3, pp. 239-248, 2009.

[12] M. Sain, S. H. Park, F. Suhara, and S. Law, "Flame retardant and mechanical properties of natural fibre-PP composites containing magnesium hydroxide," Polymer Degradation and Stability, vol. 83, no. 2, pp. 363-367, 2004.

[13] K. R. Cordell, “Waterproof fabric,” US Patent 6,274,520, 2001.

[14] W. L. Morrison, "Antimicrobial blended yarns and fabrics comprised of naturally occurring fibers," US Patent 3,959,556, 1976.

[15] W.-L. Tian, Y.-Q. Wu, W.-X. Peng, and Y.-C. Hu, "Study on lowtoxicity fire-retardant treated technology of wood," in Proceedings of the 3rd International Conference on Bioinformatics and Biomedical Engineering (ICBBE '09), pp. 1-5, Beijing, China, June 2009.

[16] C. L. Kissel, "Antistatic textile compositions and sol/gel/polymer compositions," US Patent 5,004,563, 1991.

[17] H.-S. Yang, D.-J. Kim, and H.-J. Kim, "Rice straw-wood particle composite for sound absorbing wooden construction materials," Bioresource Technology, vol. 86, no. 2, pp. 117-121, 2003.

[18] H. C. He and C. Chen, "Study on forming process of plant fiber multilayer decorative board (I)- Effect of fiber content on the properties," Applied Mechanics and Materials, vol. 468, pp. 3-7, 2014.

[19] R. Arpón, J. M. Molina, R. A. Saravanan, C. García-Cordovilla, E. Louis, and J. Narciso, "Thermal expansion behaviour of aluminium/SiC composites with bimodal particle distributions," Acta Materialia, vol. 51, no. 11, pp. 3145-3156, 2003. 

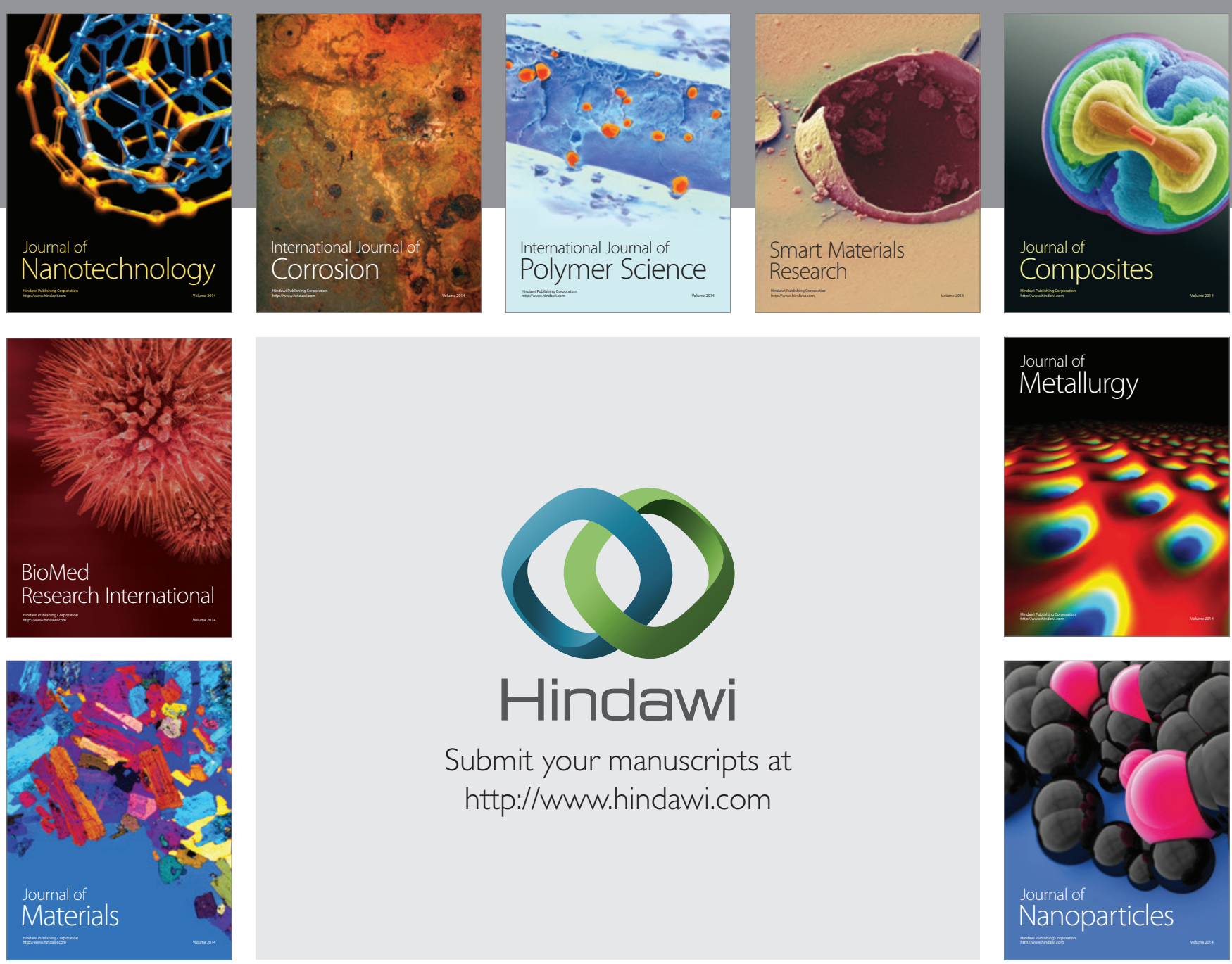

Submit your manuscripts at http://www.hindawi.com
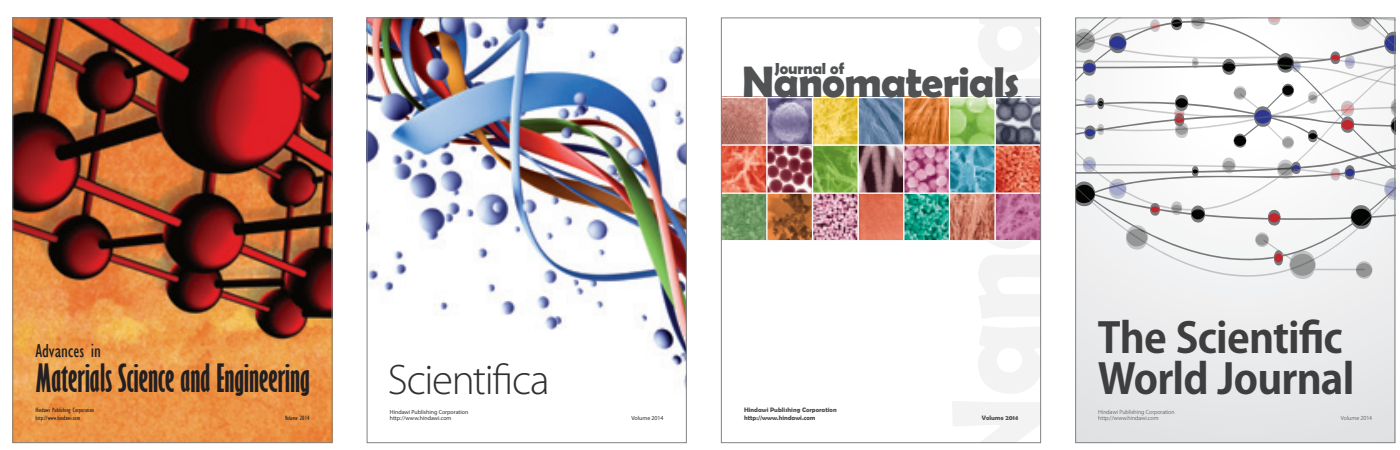

\section{The Scientific World Journal}
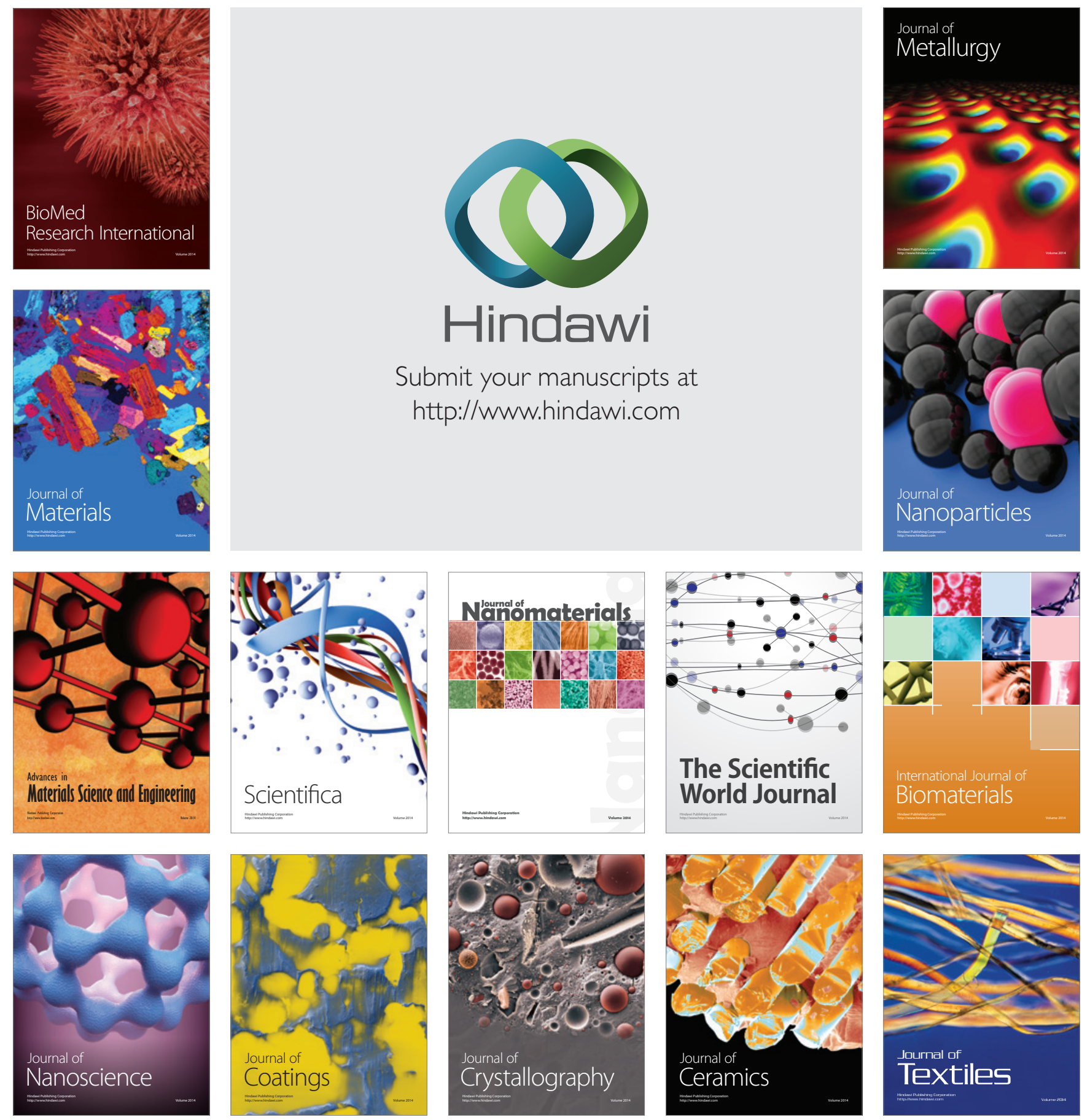